It is intended as a broad purpose underwater tool for the engineer and research worker at continental shelf depths, and carries two men. The makers claim that its performance "covers all aspects of undersea work including bottom surveys of sea-bed conditions before, during, and after laying of oil and gas pipelines and submarine cables". They also see applications for geology, marine biology, fish farming, surveillance, and as a search and recovery vehicle. There are provisions for outside manipulations and coring. (It might well have come in handy as an aid in the hazardous operation to recover the Royal Navy Buccaneer that plunged into $300 \mathrm{ft}$. of water off the Lizard a couple of years ago.)

To do all this, a cylindrical pressure vessel of $5 \frac{1}{4} \mathrm{ft}$. diameter with $1 \frac{1}{8}$ in. thick mild steel walls has been chosen. This has a theoretical collapse depth of 3,500 ft. The pressure hull is enclosed in a glass fibre shell to make SURV as rugged to surface treatment as a glass fibre boat. The prototype has been rated for 260 p.s.i., equivalent to $600 \mathrm{ft}$. depth, and is expected to be progressively reclassified down to $1,000 \mathrm{ft}$. which lies within its design safety factor. The crew environment is "near normal", that is, they breathe air at atmospheric pressure, and submerged endurance is $36 \mathrm{~h}$ which in an emergency could be extended to $48 \mathrm{~h}$ if the crew sit still. Arrangements for neutral buoyancy and two independently rotatable motors mounted on each side give the craft exceptional manoeuvrability. It can move forward and backward, turn and keep station at a given depth-in addition of course to vertical manoeuvres-all of which was convincingly demonstrated in the Lintott tank last week. It is not exactly nippy, however. Maximum speed is $2 \frac{1}{2}$ knots submerged or at the surface. For surveying this is still a considerable gain on the free diver's performance. In air, SURV weighs $6 \cdot 1$ tons excluding crew, not likely to impose much strain on harbour facilities or support ships and so qualifying it for operations in almost any dart of the world, the sponsors hope.

The cost of preparing the first SURV for operations is understood to be about $£ 60,000$-roughly 50 per cent of the cost of similar American submersibles, of which General Dynamics' vehicle is the nearest in design. At present SURV's sponsors look to hire rather than outright purchase to recoup their outlay. Hire price, which includes their own "driver", is negotiable but likely to fall within the range $£ 300-£ 400$ per day. So far, they have enquiries but no firm offers. The presence of two members of the National Institute for Oceanography at the demonstration was considered encouraging.

\section{World Health}

Within the past few years there has been unhappy evidence that some diseases, far from declining as public health standards improve, are actually increasing. Cholera El Tor, plague, yellow fever, trypanosomiasis, ancylosomiasis, viral hepatitis and venereal disease have all increased, according to the third report on world health, compiled by the World Health Organization (WHO, Geneva, $£ 1$ 15s.). Against this must be set some real achievements-tuberculosis, for example, which killed one person in nine in the United Kingdom at the turn of the century, caused only one death in 180 between 1960 and 1964. But there is a great discrepancy between the achievements of the developed countries and those of the underdeveloped world. Europe has been free of cholera since 1923, but during the past ten years it has flared up again in India and Africa. Until 1960 there was a decline, from 212,000 cases in 1950 to 33,000 in 1960 , but since then the disease has come back strongly, with a total of 94,000 cases in 1964; the worst hit countries are India and the Philippines.

There is clearly no room for complacency when diseases can re-establish themselves as strongly as that. But the underlying trend is more hopeful; infant mortality rates, always a good indicator of public health standards, show improvements almost everywhere. In some cases the improvement is dramatic, with mortality rates down by 50 per cent or more. Other countries show smaller improvements, in some cases because mortality rates for babies were already low, but many developed countries which have achieved low rates have reduced them even further. New Zealand shows a reduction in infant mortality of 18.7 per cent since 1954, and Canada a reduction of $17 \cdot 6$ per cent. Crude death rates also show a reduction in recent years, with some interesting exceptions. The United States, Argentina and Cuba all show increases of death rate since 1954, and in Europe death rates have tended to remain much the same over the past decade. Elsewhere, decreases have been common.

In developed countries, cardiovascular diseases account for about 40 per cent of all deaths. High blood pressure, the report reveals, is almost universal; only a few very primitive populations and populations living at high altitude are free from it. Cancers of the respiratory system have also become a serious health hazard; in the UK deaths from cancers of this type have increased by 69 per cent since 1954 . But there are some striking variations between countries which might be expected to be similar; in Finland the death rate per 100,000 for respiratory cancers was $58 \cdot 1$ in 1963 , while in Norway the figure was only $18 \cdot 7$.

Accidents, while not strictly a health problem, are becoming more and more important as a cause of death. In the age group from 1 to 35 , they now rank as the leading cause of death. In developing countries, accidents are less significant, but they are beginning to increase in importance, and sometimes rank as the sixth or seventh commonest cause of death.

\section{Response to Aldabra}

THose who have been campaigning, in the weeks past, to dissuade the British Government from using the island of Aldabra as an air staging post seem now to be entirely willing to press for the facilities that will be needed if the island ecosystem is to be properly studied. It seems, however, to be agreed that the first step should be a clarification of the political status of the island. Administratively, the island comes under the umbrella of the British Indian Ocean Territory, which was originally created for defence purposes. Obviously the British Government could do much to reassure the ecologists by formally detaching Aldabra from that organization.

As yet there is no plan for the long-term conservation of Aldabra, but the Royal Society is eager to help in preparing one. The Nature Conservancy is also a 